\title{
ESTUDO EPIDEMIOLÓGICO: PERCEPÇÃO DOS ESTUDANTES DE MEDICINA VETERINÁRIA DA UFLA SOBRE EXPOSIÇÃO A FATORES DE RISCO E ESTADO VACINAL FRENTE AO TÉTANO
}

(EPIDEMIOLOGICAL STUDIES: PERCEPTIONS OF VETERINARY MEDICINE UFLA

STUDENTS ON EXPOSURE AND RISK FACTORS IN THE FACE OF TETANUS VACCINE STATE)

\author{
N. A. AMBRÓSIO ${ }^{*}$, F. DA C. DIAS ${ }^{2}$, L. A. CASTRO ${ }^{2}$, M. P. BOTTINO ${ }^{1}$, D. DE C. \\ ANDRADE ${ }^{2}$, M. F. M. ROCHA ${ }^{3}$
}

O tétano é uma doença bastante difundida no mundo, causada pela toxina produzida pelo Clostridium tetani, acometendo diversas espécies, incluindo o homem. Alguns fatores, como ambiente, ocupação e perfil vacinal, entre outros, determinam o perfil epidemiológico. Diante da importância que o tétano representa em saúde pública, e seu possível caráter ocupacional, avaliou-se a percepção dos estudantes de Medicina Veterinária da UFLA sobre exposição a fatores de risco e estado vacinal frente ao tétano. Foi utilizado como ferramenta de avaliação um questionário composto por questões relacionadas ao conhecimento da doença em humanos e em outros animais. A amostra deste estudo foi composta por 149 graduandos voluntários, e o questionário foi aplicado a todos os períodos do curso de Medicina Veterinária no segundo semestre de 2011. Os alunos foram separados em dois grupos, utilizando como critério de classificação a disciplina que aborda o tema da pesquisa. O primeiro grupo foi composto por uma amostra de 55 alunos que não cursaram e o segundo por 94 alunos que cursaram a disciplina. Os resultados foram obtidos através de uma análise descritiva dos dados coletados. Verificou-se que $24 \%$ dos participantes não souberam dizer quando receberam a vacinação, e também apresentaram um desconhecimento do período médio de cobertura vacinal, sendo que $25,5 \%$ responderam que era de 10 anos. Entre os que responderam ao questionário, 54,41\% acreditam que o tétano seja uma doença ocupacional, sendo mais mencionados os profissionais da área de agrárias, devido ao constante contato com terra e materiais enferrujados, fatores de risco mais citados pelos graduandos. Observou-se um maior conhecimento sobre a doença pelos estudantes mais avançados no curso de Medicina Veterinária quando questionados a respeito de saúde animal. Já em saúde humana, notou-se uma homogeneidade nas respostas das questões de todos os graduandos.

\section{APOIO: CNPq e FAPEMIG}

